\title{
Regional blood flow and the localisation of lymphoblasts in the small intestine of the mouse: effect of an elemental diet
}

\author{
C A OTTAWAY AND D M V PARROTT
}

From the Department of Medicine, St. Michaels Hospital, University of Toronto, Toronto, Canada, and the Department of Bacteriology and Immunology, Western Infirmary, University of Glasgow, Glasgow, Scotland

SUMmARY To test the hypothesis that food antigens influence the in vivo migration of lymphoblasts to the small intestine, the effect of an elemental diet (Vivonex) on the distribution of lymphoblasts within the small intestine of mice has been examined. Viable lymphoblasts from the mesenteric nodes of conventionally fed animals were labelled in vitro and given intravenously to recipient mice fed either a standard diet or elemental diet. The localisation of these cells within the small intestine was altered in the animals fed the elemental diet but only in the distal half of the small intestine. The relationship of the localisation of blast cells to the delivery of cardiac output along the small intestine was examined by assessing cell localisation in conjunction with the distribution of an isotopic indicator $\left.{ }^{86} \mathrm{RbCl}\right)$. The results show that the pattern of localisation of lymphoblasts within the small intestine is related to the probability that they will be delivered to different regions by the blood stream. Therefore, the alterations in blast localisation in the small intestine of animals of the elemental diet can be viewed as a consequence of changes in the perfusion of the distal small intestine. These results do not support the concept that antigens directly influence the efficiency with which blast cells migrate into the intestinal mucosa.

The continued effectiveness of immune responses in the intestinal mucosa depends upon the arrival of antigen primed effector cells (lymphoblasts) by way of the blood stream. Precursor cells stimulated by antigen in the gut lymphoid tissue ${ }^{1}$ must travel via abdominal and thoracic lymphatics and the general circulation to reach the gut mucosa. The lymphoid tissue in which a lymphoblast is stimulated has an important influence on the destinations in which it may be found after its vascular journey. Labelled lymphoblasts from the thoracic duct lymph, ${ }^{2}$ intestinal lymph, ${ }^{3}$ and mesenteric lymph nodes ${ }^{46}$ have all been found to have a propensity to migrate to the small intestinal mucosa after intravenous transfer, although the factors which control this migration are still incompletely understood.

The presence of antigen from the intestinal lumen has been proposed to be a major determinant of the accumulation of lymphoid effector cells within the intestine. ${ }^{78}$ Consistent with this hypothesis are

Received for publication 2 December 1980. observations that localised high densities of specific IgA bearing cells can be found in segments of small intestine subjected to local application of antigen in sheep ${ }^{9}$ and rats. ${ }^{8}$ However, lymphoblasts can also migrate to the small intestine in the apparent absence of exogenous antigen. Thoracic duct lymphoblasts will migrate to rat neonatal intestine $\mathrm{e}^{10}$ and lymphoblasts from mesenteric nodes or the thoracic duct will migrate to antigen free gut grafts in mice. ${ }^{45}$ The known unevenness of the distribution of the progeny of B-lymphoblasts (immunoglobulin producing cells) along the small intestine is an additional perplexing feature. Studies in humans, ${ }^{11}$ mice, ${ }^{72}$ calves, ${ }^{13}$ pigs, ${ }^{14}$ and rats ${ }^{8}$ have demonstrated higher densities of immunoglobulin containing cells in the proximal small intestine with decreasing numbers of cells in the ileum. This asymmetry has been attributed to the greater stimulation of the proximal small intestine by food antigens. ${ }^{812}$

In this study we examine the potential influence of food antigens by comparing the localisation of mesenteric lymphoblasts in the small intestine of 
mice raised on either a conventional rodent diet or a chemically defined non-immunogenic diet (Vivonex). ${ }^{15}$

\section{Methods}

\section{MICE}

Seven to 14 week old mice of inbred NIH strain (H-2q) maintained in this department were used. Mice of the same age and sex were used within each experiment.

\section{DIET}

Control animals were fed a pellet diet (BP Rat and Mouse No. 1 maintenance diet 801 160W, BP Nutrition) ad libitum. The test animals were allowed free access to a chemically defined elemental diet (Vivonex Standard, Eaton Laboratories) which was prepared as an agar gel. ${ }^{16}$ Vivonex contains nitrogen in the form of amino acids, carbohydrate as hexose sugars, essential fatty acids as safflower oil mineral and vitamins and is considered to be non-immunogenic. ${ }^{15}$ Mice were weaned onto either the pellet or elemental diet at 16-17 days of age and maintained on them for at least four weeks before experimentation.

\section{MEASUREMENT OF CARDIAC OUTPUT}

DISTRIBUTION ( \% CO)

Cardiac output distribution was assessed by a modification of the ${ }^{86}$ Rubidium chloride fractionation method as previously described. ${ }^{17}$ Briefly, a measured volume of ${ }^{86} \mathrm{RbCl}$ diluted in $0.9 \%$ saline was injected through an intravenous catheter in the lateral tail vein of the mouse. This was flushed through with an equal volume of saline and after 45 seconds the animal was killed with an injection of saturated potassium chloride through the same catheter. That portion of the intravenous dose of ${ }^{86} \mathrm{Rb}$ activity which is found in a particular tissue can be taken as a measure of the fractional distribution of the cardiac output which is received by that tissue. ${ }^{17} 18$

\section{CELL SUSPENSIONS}

Mesenteric lymph node cells (MLN) from pellet fed animals were prepared at room temperature by gentle teasing of the lymph nodes in RPMI-1640 medium (Gibco Biocult Ltd., Glasgow) containing $5 \%$ foetal calf serum (FCS) (Gibco Biocult Ltd). The cell suspensions were filtered through glass wool to remove debris and the number of viable cells in suspension was determined by their ability to exclude $0.2 \%$ eosin. MLN suspensions enriched in T cells (T-MLN) were prepared using nylon wool columns by the method of Greaves and Brown. ${ }^{10}$ The proportion of cells specifically killed by an antiserum against NIH thymocytes was determined as previously described..$^{20}$ Antiserum against NIH thymocytes was prepared in rabbits as described previously. ${ }^{20}$ This was used to assess the specific killing of lymphoid cells in the presence of guinea-pig complement (Wellcome Laboratories). The antiserum showed a specific killing of NIH thymocytes $98 \%$, bone marrow cells $2-4 \%$, MLN cells $49-53 \%$, and nylon-wool separated MLN cells $93-95 \%$ and was considered to be an anti-T cell serum.

\section{In vitro LABELLING OF CELLS}

Cell suspensions were incubated with the thymidine analogue ( $\left.{ }^{125} I\right)$-5-iodo-2-deoxyuridine $\left({ }^{125} I U d R\right)$ (Radiochemical Centre, Amersham, UK) to label blast cells undergoing DNA synthesis. Incubations were carried out in RPMI-1640 containing $5 \%$ FCS and $0.5 \mu \mathrm{Ci}^{125} \mathrm{IUdR}$ per $10^{7}$ viable cells per $\mathrm{ml}$ at $37^{\circ}$ for 60 minutes in a shaking water bath. After labelling, the cells were washed three times in fresh medium (RPMI-1640 without FCS) and injection doses of $1 \cdot 5-2 \times 10^{7}$ viable cells were administered to the animals through a lateral tail vein. Multiple samples of each injection preparation were retained for counting the administered radioactivity. Twentyfour hours after the cell transfer, animals were killed with or without simultaneous assessment of the ${ }^{86} \mathrm{RbCl}$ distribution.

\section{TISSUE PREPARATION}

Tissues were dissected immediately after the animals were killed and placed in containers for weighing and counting. The small intestine was removed in one piece and then cut into four equal lengths which were labelled segments 1-4 from proximal to distal. Peyer's patches were identified and excised from the small intestine before further manipulation or counting. Each length of small intestine was gently manipulated with forceps and washed in saline to remove faeces. We have shown previously that this method of preparing the intestine does not lead to any loss of blast cell label or rubidium label from the intestine and that the distribution of the labels within different regions of the intestine are not disturbed by this preparation. ${ }^{21}$

\section{COUNTING METHODS}

Radioactivity was measured on a dual channel gamma counter as previously described.17 The amount of blast cell label or rubidium which was found in a particular tissue was expressed as a percentage of the amount which was injected into the animal. ${ }^{17}$ We have shown previously that the two labels can be resolved from one another and that 
blast cell localisation estimates are not influenced by the presence of the ${ }^{86} \mathrm{Rb}$ activity. ${ }^{17}$

\section{STATISTICAL TESTS}

The difference in means was assessed using Student's $t$ test. Regression analysis and correlation coefficients $(r)$ were determined by standard methods. ${ }^{22}$ The level of significance of a correlation coefficient-that is, the probability that the observed correlation coefficient could have arisen by chance-was assessed with Student's $t$ test. ${ }^{23}$

\section{EXPERIMENTS AND RESULTS}

Mice fed the elemental diet ate well and appeared normal and healthy throughout the period of experiments. This is consistent with previous reports, ${ }^{1624}$ as is the finding that both the total weight of the elemental diet fed mice and the wet weight of their lymphoid tissues was less than that of matched animals fed a conventional diet (Table 1). The wet weight of the caecum and large intestine of mice fed elemental diet was also significantly less than that of pellet fed animals, but there was no change evident in the weight of the small intestine (Table 1). The only other organ to show a difference in weight in the elemental diet fed animals was the liver. The liver was increased in weight and found to have substantial fatty deposits in the elemental diet fed animals which confirms the finding of Ferguson and her co-workers. ${ }^{1624}$

\section{EFFECTS OF ELEMENTAL DIET ON FRACTIONAL DISTRIBUTION OF CARDIAC OUTPUT}

We examined the distribution of the cardiac output in mice raised on the two diets, because alterations in regional blood flow can be an important modulator of the levels of lymphoblast localisation. ${ }^{17}{ }^{21}$ Significantly less of the cardiac output was delivered to the MLN and spleen as well as to the caecum and large intestine in the mice fed the elemental diet than mice fed normal pellet diet. This is in keeping with the reduced mass of these organs. The fraction of the cardiac output received by the whole of the small intestine, however, was not influenced by the difference in diets (Table 1).

\section{EFFECTS OF ELEMENTAL DIET ON LOCALISATION OF MESENTERIC}

LYMPHOBLASTS IN SMALL INTESTESTINE

As the fraction of the cardiac output going to the small intestine was the same in animals fed either the pellet or elemental diets, the opportunity for transferred lymphoblasts to be delivered to the small intestine should be the same in each of these groups of animals. To assess whether the absence of
Table 1 Effects of elemental diet on abdominal organs and lymphoid tissue

\begin{tabular}{|c|c|c|c|}
\hline & \multicolumn{2}{|l|}{ Diet } & \multirow[t]{2}{*}{$P *$} \\
\hline & Pellet $(n=5)$ & Elemental $(n=6)$ & \\
\hline Weight of mouse (g) & $25 \cdot 8 \pm 1 \cdot 1$ & $23 \cdot 3 \pm 0 \cdot 5$ & $<0.01$ \\
\hline \multicolumn{4}{|c|}{ Weight of organs (mg) } \\
\hline MLN & $184 \pm 37$ & $132 \pm 26$ & $<0.05$ \\
\hline Spleen & $106 \pm 6$ & $65 \pm 9$ & $<0.001$ \\
\hline Small intestine & $1406 \pm 62$ & $1343 \pm 95$ & \\
\hline Caecum & $208 \pm 30$ & $133 \pm 21$ & $<01$ \\
\hline Large intestine & $419 \pm 35$ & $349 \pm 41$ & $<0.05$ \\
\hline \multicolumn{4}{|c|}{ Percent cardiac output } \\
\hline MLN & $0.74 \pm 0.26$ & $0 \cdot 40 \pm 0 \cdot 10$ & $<0.05$ \\
\hline Spleen & $0 \cdot 54 \pm \cdot 15$ & $0.24 \pm 0.11$ & $<0.01$ \\
\hline Small intestine & $14 \cdot 9 \pm 1 \cdot 5$ & $14 \cdot 9 \pm 2 \cdot 3$ & \\
\hline Caecum & $1.8 \pm 0.6$ & $0.9 \pm 0.3$ & $<0.01$ \\
\hline Large intestine & $4.0 \pm 0.4$ & $2 \cdot 8 \pm 0 \cdot 8$ & $<0.05$ \\
\hline
\end{tabular}

-Measurements are the mean \pm SD for each group.

†Significance of difference for comparison of the two diets.

Table 2 Effects of elemental diet on 24 hour localisation of ${ }^{125}$ IUDR labelled MLN to abdominal organs*

\begin{tabular}{llll}
\hline $\begin{array}{l}\text { Experiment and } \\
\text { tissue }\end{array}$ & \multicolumn{2}{c}{ Diet } & \\
\cline { 2 - 3 } & $\begin{array}{l}\text { Pellet } \\
(\text { mean } \pm S D)\end{array}$ & $\begin{array}{l}\text { Elemental } \\
\text { (mean } \pm S D)\end{array}$ & \\
\hline 1 (n=8 in each group) & & \\
MLN & $0.38 \pm 0.04$ & $0.21 \pm 0.03$ & 0.001 \\
Small intestine & $3.6 \pm 0.4$ & $3.6 \pm 0.4$ & \\
Caecum & $0.49 \pm 0.14$ & $0.24 \pm 0.04$ & 0.001 \\
Large intestine & $0.74 \pm 0.22$ & $0.57 \pm 0.12$ & \\
2 (n=5 in each group) & $0.73 \pm 0.06$ & $0.53 \pm 0.12$ & 0.05 \\
MLN & $5.0 \pm 0.3$ & $4.8 \pm 0.5$ & \\
Small intestine & $0.49 \pm 0.17$ & $0.22 \pm 0.05$ & 0.05 \\
Caecum & $0.73 \pm 0.35$ & $0.53 \pm 0.19$ & \\
Large intestine & 0.53 &
\end{tabular}

*125IUDR labelled MLN from pellet fed mice.

†Significance of difference for comparison of the two diets.

macromolecular food antigens in the elemental diet fed animals decreased the attractiveness of the small intestine for intravenously transferred blast cells, migration experiments were carried out in pellet and elemental diet fed animals (Table 2). Significantly less blast cell label was found in the mesenteric nodes and the caecum of the elemental diet fed animals. The proportion of the injected dose which was found in the small intestine, however (Table 2), was the same in both groups of animals. There was also no significant difference in the percentage of the injected blast label found in the spleen or other organs (results not shown) in animals fed elemental or pellet diets. This suggests that the accumulation of lymphoblasts in the small intestine as a whole is not substantially influenced by the presence of macromolecular antigens in the ingested food. 
MESENTERIC LYMPHOBLAST LOCALISATION AND REGIONAL BLOOD FLOW WITHIN

SMALL INTESTINE

We have shown previously that there is a gradient of both blast cell localisation and the fraction of the cardiac output which is received by different regions of the small intestine in conventionally fed mice. ${ }^{20}$ Moreover, when both distributions are assessed concurrently in normal mice, there is a significant correlation between the pattern of lymphoblast localisation and the distribution of the cardiac output along the length of the small intestine. ${ }^{21}$ But neither the total accumulation of lymphoblasts or the fraction of the cardiac output going to the whole small intestine was found to be altered in mice fed the elemental diet (Tables 1 and 2). If, therefore, the presence of food antigens in the proximal small intestine contributes to the increased localisation of blast cells normally observed in that part of the small intestine, then the number of lymphoblasts going to different regions of the small intestine should be altered in the animals fed the elemental diet. To test this possibility, the localisation of
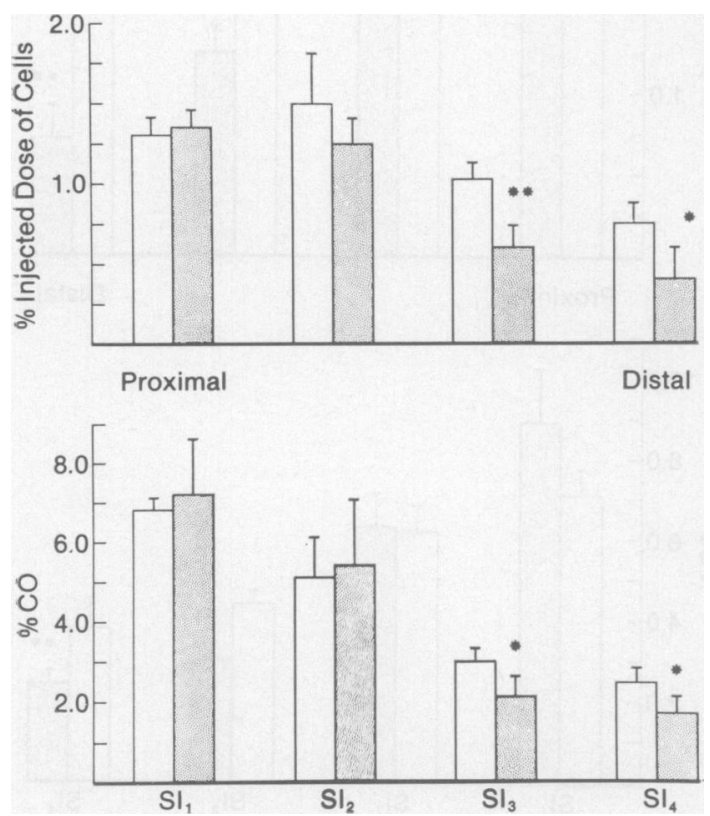

Fig. 1 The 24 hour localisation of (125I) UdR $M L N$ from peilet fed mice (top) and the percentage of the cardiac output (bottom) in different segments of the small intestine. The results are the mean $( \pm S D)$ of seven animals fed pellet diet (open areas) and five animals fed elemental diet (stippled areas). ${ }^{*} \mathrm{P} 0.05$, ${ }^{* *} \mathrm{P} 0.01$ for the difference between elemental and pellet diet segments.
Table 3 Results of regression analysis of $\left({ }^{125} I\right)-U d R$ $M L N$ lymphoblast localisation and fractional blood flow for small intestine segments in pellet fed and elemental diet fed mice

\begin{tabular}{lll}
\hline & \multicolumn{2}{l}{ Diet } \\
\cline { 2 - 3 } & Pellet & Elemental \\
\hline Segments analysed (no.) & 28 & 20 \\
$\begin{array}{l}\text { Correlation coefficient } \\
\text { Slope of regression line }\end{array}$ & 0.60 & 0.70 \\
$\begin{array}{l}\text { (\% cells } / \% \text { CO) } \\
\text { P: probably that correlation }\end{array}$ & 0.11 & 0.12 \\
is due to chance & $<0.001$ & $<0.001$ \\
\hline
\end{tabular}

lymphoblasts was examined in conjunction with regional blood flow in segments of the small intestine of animals on the two diets (Fig. 1). This showed that the distribution of lymphoblasts within the small intestine was altered in the animals fed the elemental diet, but only in the distal regions of the small intestine (Fig. 1) was there a significant decrease in the localisation of lymphoblasts and not the proximal regions of the small intestine of mice on the elemental diet compared with those fed pellets. There was also a significant decrease in the fraction of the cardiac output received by the lower half of the small intestine in the animals fed the elemental diet (Fig. 1). Regression analysis of the segmental lymphoblast localisation and the fraction of the cardiac output delivered to different regions of the small intestine showed that there was the same degree of correlation between these phenomena in both diet groups (Table 3).

COMPARISON OF UNSEPARATED AND T-ENRICHED MESENTERIC LYMPHOBLAST POPULATIONS

Lymphoblasts of T-enriched populations of mesenteric node cells are known to accumulate in the small intestine to an even greater extent than do unseparated lymphoblasts, ${ }^{6}{ }^{21}$ The localisation of unseparated MLN lymphoblasts along the intestine was compared with that of a T-MLN lymphoblast population in pellet fed animals (Fig. 2). There was approximately twice as much lymphoblast label found in each segment of the small intestine after transfer of the T-enriched blast cells compared with unseparated MLN blasts, but a similar gradient was apparent in the proximal to distal distribution of the recovered label (Fig. 2). In each case the gradient along the small intestine paralleled that of the distribution of regional blood flow along the small intestine (Fig. 2). We wished to examine whether this increased tendency of lymphoblasts from a T-enriched MLN preparation to localise in the small intestine would reveal differences in the proximal small intestine segments of animals fed the elemental 
diet which were not apparent in the experiments with unseparated MLN blast cells. Comparison of the localisation of T-MLN lymphoblasts in elemental diet and pellet fed animals (Fig. 3) showed that localisation was altered only in the distal regions of the small intestine. The decreased accumulation of cell label in the distal segments was again associated with a reduction of the proportional delivery of cardiac output to those portions of the small intestine (Fig. 3).

\section{Discussion}

The purpose of this study was to investigate the potential contribution of macromolecular food antigens to the localisation of mesenteric lympho-
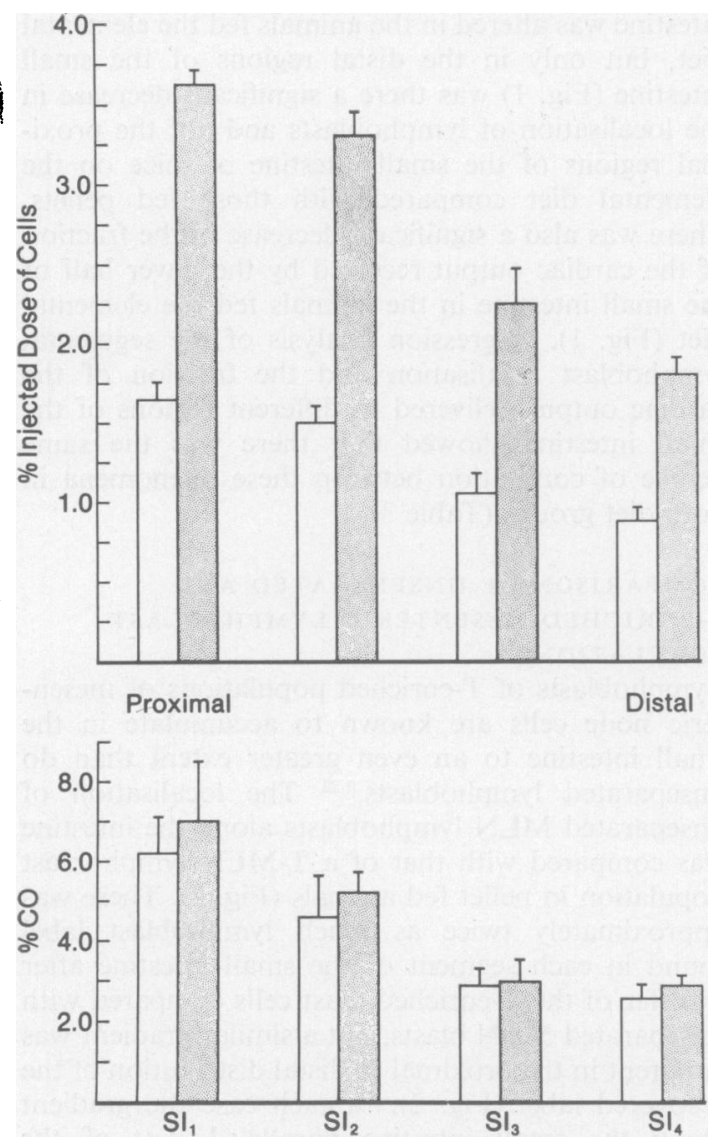

Fig. 2 The 24 hour localisation of unseparated (125I) UdR MLN (open areas) or nylon wool separated (125I) UdR MLN lymphoblasts from pellet fed mice (stippled areas) and the percentage of the cardiac ouiput received by different segments of the small intestine in pellet fed animals. The results are the means $( \pm S D)$ for six animals in each group. blasts within the small intestine of mice. If food antigens normally influence the migration of lymphoblasts to the small intestine, then mice fed an elemental diet should show a decrease in the total accumulation of blast cells and/or a redistribution of their localisation pattern such that fewer cells would be found in the proximal small intestine compared with conventional animals. The total amount of blast cell label found in the small intestine was the same in pellet and elemental diet fed animals (Table 2 ), and there was no decrease in the amount of blast
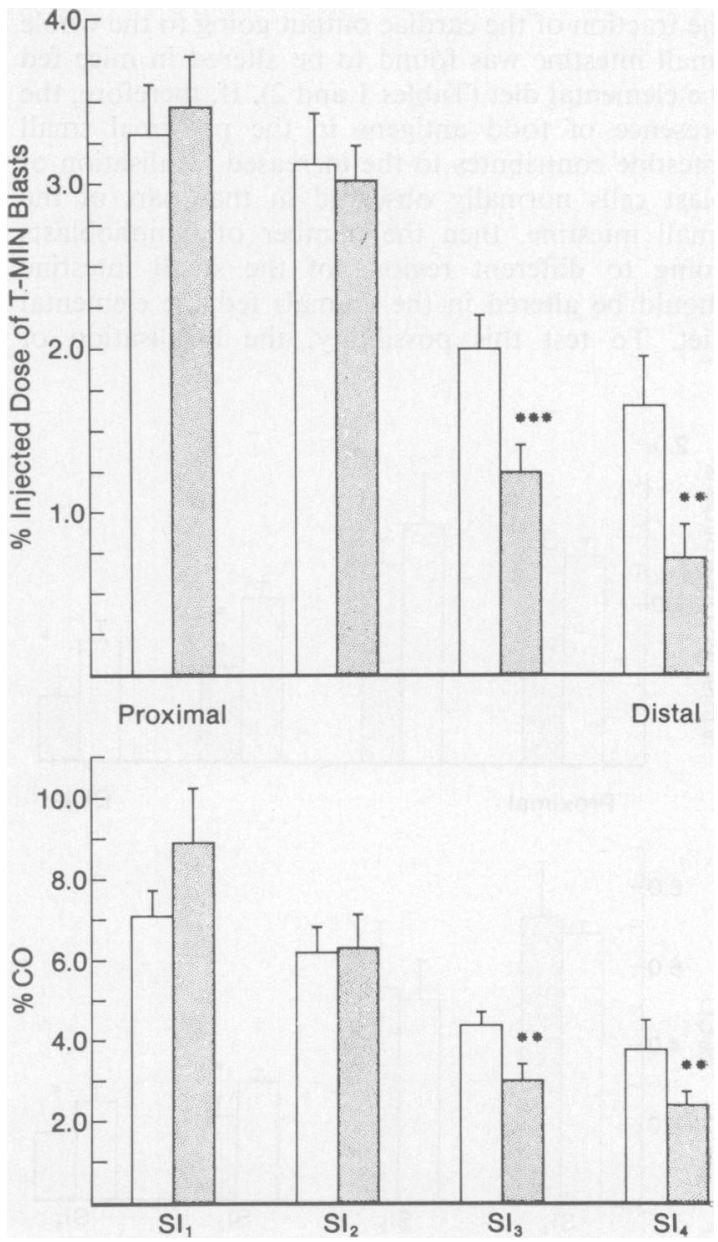

Fig. 3 The effect of diet on the 24 hour localisation of nylon wool separated ( $\left.{ }^{125} I\right)$ UdR-MLN from pellet fed mice and the percentage of the cardiac output delivered to different segments of the small intestine. The results are the means $( \pm S D$ ) in each group of pellet fed (open areas) or elemental diet fed (stippled areas) for five animals in each group .**P 0.01 and ${ }^{* * *} \mathrm{P} 0.001$ for the comparison of segments from elemental diet and pellet fed animals. 
localisation found in the proximal small bowel (Figs. 1 and 3). These findings show that food antigens are not a major determinant of lymphoblast localisation in the small intestine.

The opportunity for injected blast cells to be delivered to the small intestine was also assessed in these experiments by measuring the fraction of the cardiac output received by the whole small intestine. This was found to be the same for animals on the two different diets (Table 1). We have demonstrated previously that, when the distribution of blood flow and the localisation of lymphoblasts along the small intestine are examined concurrently in pellet fed animals, there is a significant correlation between these two phenomena which is not affected by the time after the injection of cells at which the distributions are assessed. ${ }^{21}$ Here, the localisation of mesenteric lymphoblasts was found to have a similar relationship to the partition of blood flow within the small intestine in both pellet and elemental diet fed animals (Table 3). This was so in spite of significant reduction in both blast localisation and regional blood flow in the distal small intestine of the mice fed the elemental diet. The localisation of T-MLN blasts also paralleled the gradient of cardiac output along the small intestine in both groups of animals (Figs. 2 and 3). We conclude, therefore, that factors which govern the way in which a given population of blast cells migrates into the small intestine is similar throughout the small intestine and that the higher level of lymphoblast localisation in the upper small bowel is principally the result of the greater opportunity that blood borne cells have of being delivered to that region.

The findings presented here support the view ${ }^{3-6}$ that the deployment of lymphoblasts within the small intestine is primarily determined by the origin and nature of the lymphoblast population and not by antigen-dependent processes-at least, not those present in a normal diet. It should be emphasised, however, that macromolecular food antigens could influence the number of effector cells present in a particular site by stimulating cell division. Husband and Gowans ${ }^{8}$ have demonstrated that some proliferation of antibody containing cells can occur in a region of intestine challenged locally, but we have not tested whether the lifespan of effector cells in the intestinal mucosa is altered in mice fed on elemental diet, nor have we tested whether any of the constituents in an elemental diet such as Vivonex could function as haptens and, if linked to a self protein, provide an immune stimulus to the upper portion of the intestine, though it seems unlikely that mesenteric lymphoblasts from normal pellet fed mice would respond to such a stimulus.

The present experiments show that alteration in diet can influence the regional delivery of effector cells in the distal small intestine and elsewhere along the gut tract as a consequence of changes in regional blood flow. This suggests, as have others ${ }^{16}{ }^{24}$, that the concept of resting the bowel through dietary manipulations may have important immunological changes locally in the gut.

We are grateful to Eaton Laboratories for providing the Vivonex at reduced cost. We thank Mrs S MacKenzie for her skilled technical assistance. This work was supported by MRC Grant $977 / 623 /$ S (UK) and MRC Grant 465/321 (Canada).

\section{References}

${ }^{1}$ Craig SW, Cebra JJ. Peyers patches: an enriched source of precursors for IgA producing immunocytes in the rabbit. J Exp Med 1971; 134: 188-200.

${ }^{2}$ Gowans JL, Knight EJ. The route of recirculation of lymphocytes in the rat. Proc $R$ Soc B 1964; 159: 257-82.

${ }^{3}$ Hall JG, Hopkins J, Orlans E. Studies on the lymphocytes of sheep: III Destination of lymph borne immunoblasts in relation to their tissue of origin. Eur J Immunol 1977; 7: 30-7.

${ }^{4}$ Parrott DMV, Ferguson A. Selective migration of lymphoblasts within the mouse small intestine. Immunology 1974; 26: 571-87.

${ }^{5}$ Guy-Grand D, Griscelli C, Vassalli P. The gut associated lymphoid system: nature and properties of the large dividing cells. Eur J Immunol 1974; 4: 435-43.

${ }^{6}$ Rose ML, Parrott DMV, Bruce RG. Migration of lymphoblasts to the small intestine. II Divergent migrations of mesenteric and peripheral immunoblasts to sites of inflammation in the mouse. Cell Immunol 1976; 27 : 36-46.

${ }^{7}$ Crabbé PA, Bazin H, Eyssen H, Heremans JF. The normal microbial flora as a major stimulus for the proliferation of plasma cells synthesizing IgA in the gut. Int Arch Allergy 1968; 34: 362-75.

${ }^{8}$ Husband AJ, Gowans JL. The origin and antigendependent distribution of IgA-containing cells in the intestine. $J$ Exp Med 1978; 148: 1146-60.

${ }^{\circ} \mathrm{Husband}$ AJ, Lascelles AK. The origin of antibody in intestinal secretions of the sheep. Aust J Exp Biol Med Sci 1974; 52: 791-9.

${ }^{10}$ Halstead TE, Hall JG. The homing of lymph-borne immunoblasts to the small intestine of neonatal rats. Transplantation 1972; 14: 339-46.

${ }^{11}$ Brandtzaeg P, Baklien $\mathrm{K}$. Immunoglobulin producing cells in the intestine in health and disease. Clin Gastroenterol 1976; 5: 251-69.

${ }^{12}$ Lange S, Nygren $\mathbf{H}$, Svennerhelm A, Holmgren $\mathbf{J}$. Antitoxic cholera immunity in mice: Influence of antigen deposition on antitoxin containing cells and selective immunity in different parts of the intestine. Infect Immunol 1980; 28: 17-23.

${ }^{13}$ Porter $P$, Noakes DE, Allen WD. Intestinal secretion of immunoglobulin in the pre-ruminant calf. Immunology 1972; 23: 299-312.

${ }^{14}$ Allen WD, Porter P. The relative frequencies and 
distribution of immunoglobulin-bearing cells in the intestinal mucosa of neonatal and weaned pigs and their significance in the development of secreting immunity. Immunology 1977; 32: 819-24.

${ }^{15}$ Russell RI. Elemental diets. Gut 1974; 16: 68-79.

${ }^{16}$ Ferguson A, Logan RA, MacDonald TT. Increased mucosal damage during parasite infection in mice fed on elemental diet. Gut 1980; 21 : 37-43.

${ }^{17}$ Ottaway CA, Parrott DMV. Regional blood flow and its relationship to lymphocyte and lymphoblast traffic during a primary immune reaction. J Exp Med 1979; 158: $218-30$.

${ }^{18}$ Sapirstein LA. Regional blood flow by fractional distribution of indicators. Am J Physiol 1958; 193: 161-8.

${ }^{19} \mathrm{Greaves}$ MF, Brown G. Purification of human T and B cells. J Immunol 1974; 112: 420-5.
${ }^{20}$ Rose ML, Parrott DMV, Bruce RG. Migration of lymphoblasts to the small intestine. I Effect of Trichinella spiralis infection on the migration of mesenteric lymphoblasts to the small intestine and mesenteric $T$ lymphoblasts in syngeneic mice. Immunology 1976; 31 : 723.

${ }^{21}$ Ottaway CA, Parrott DMV. Regional blood flow and the localization of lymphoblasts in the small intestine of the mouse. I Examination of normal small intestine. Immunology 1980; 41: 955.

${ }^{22}$ Dixon WJ, Massey FJ. Introduction to statistical analysis. New York: McGraw-Hill, 1957; 189-201.

${ }^{23}$ Moroney MJ. Facts from figures. New York: Penguin Books, 1951: 295-312.

${ }^{24}$ Ferguson A, Paul G, MacDonald TT. Immunodeficiencies and fatty liver in mice reared on an elemental diet. Arq Gastroenterol 1978; 15: 11-5. 